\title{
Reducing Cognitive Load in Learning by Analogy
}

\author{
Lindsey E. Richland ${ }^{1} \&$ Janice Hansen ${ }^{2}$ \\ ${ }^{1}$ Comparative Human Development, University of Chicago, USA \\ ${ }^{2}$ Education, University of California, Irvine, USA \\ Correspondence: Lindsey Richland, Department of Comparative Human Development, University of Chicago, IL \\ 60615, USA. Tel: 1-773-834-4114. E-mail: 1richland@uchicago.edu
}

Received: March 12, 2013

Accepted: November 8, $2013 \quad$ Online Published: November 22, 2013

doi:10.5539/ijps.v5n4p69

URL: http://dx.doi.org/10.5539/ijps.v5n4p69

\begin{abstract}
The ability to draw connections between concepts, problems, or representations is crucial to mathematical proficiency, though teachers face challenges in capitalizing on classroom opportunities to develop such connected thinking. An experiment with fifth-grade students tests theoretically grounded cuing strategies for supporting learning from instructional analogies. Posttest results indicate that an analogy between division of natural numbers and rational numbers improved students' proficiency in dividing fractions regardless of the addition of analogical cuing strategies, but that the additional cuing led to more conceptual, flexible problem solving. These cuing strategies may be effective ways to enhance students' ability to draw connections across mathematics and capitalize on classroom learning opportunities.
\end{abstract}

Keywords: analogy, cognitive science, mathematics education, division of fractions

\section{Introduction}

\subsection{Drawing Connections within Mathematics Instruction}

Drawing meaningful relationships between mathematical concepts, procedures, and problems lies at the heart of the U.S. National Research Council's multi-strand definition of mathematical proficiency (2001; National Mathematics Advisory Panel, 2008). Reflecting the views of the international research community, the NRC emphasizes that mathematical understanding requires interacting with mathematics as a connected system. Psychologically, however, the cognitive underpinnings of developing schematized, organized knowledge representations are complex and involve high processing load (see Richland, Stigler \& Holyoak, 2012). Thus while there is general agreement regarding the importance of leading students to develop richly connected mathematical knowledge, designing and implementing such instruction requires careful consideration of the psychological processes involved. Conducting classroom instruction that effectively draws on children's knowledge representations and cognitive resource capacities to enable them to draw deep conceptual connections is known to be challenging for teachers (e.g., Smith, Hughes, Engle, Stein, 2009; Stein, Engle, Smith \& Hughes, 2008).

The current paper, therefore, explores instructional analogies as one tool for making explicit connections between mathematical representations. This cognitive act is well studied, so educational design can build on existing literature regarding the necessary processing resources. Instructional analogy is the process of drawing students into making connections between the conceptual structures of two or more representations (Gentner, 1983; Richland, Holyoak \& Stigler, 2004). In mathematics, this signifies the act of finding similarities between the mathematical structures within two or more representations. Representations may include problems, concepts, solution strategies, or other non-mathematical phenomena (e.g., noting similarities between division of integers and sharing cookies among friends, or between division of integers and division with variables) (English, 1997).

\subsection{Defining Analogy}

The literature generally distinguishes between analogy, the process of finding similarities based on structural features (e.g., two problems invoking division), versus the broader case of pure similarity, which would include drawing similarities based on surface, or appearance, features (e.g., comparing two word problems using 'cookie sharing' as a context that may or may not both rely upon division) (Gentner, 1983). The latter form of similarity 
is easier and more common among novices to a domain, while experts are more likely to draw purely structural connections (Gentner \& Rattermann, 1991; Chi, Feltovich \& Glaser, 1981).

Theorists have long argued that drawing such structural similarities via analogical reasoning lies at the core of rigorous, creative mathematical thought (English, 1997; Hilbert, 1900; Polya, 1954; Skemp, 1976). Recognizing commonalities and differences across mathematical structures is a basic part of doing mathematics (Gallistel \& Gelman, 2005; Gelman \& Gallistel, 1978/1986). It is also a basic part of teaching mathematics (Alexander \& Buehl, 2004; English, 2004; Chiu \& Tron, 2004; Richland, Zur \& Holyoak, 2007).

In spite this importance of analogical thinking to mathematics, experimental research suggests that learners without high content knowledge, typically the case in a classroom context, often fail to notice or benefit from instructional analogies if they are not provided with very explicit cues that draw their attention to relational similarities (e.g., Gick \& Holyoak, 1980, 1983; Novick \& Holyoak, 1991; Reed, 1989; Ross, 1987, 1989).

Teachers are the natural candidates to provide such explicit cues to their student learners; however, research examining teacher instructional practices suggest that many teachers do not adequately provide these (Richland, Zur \& Holyoak, 2007). Further, this is particularly challenging for new teachers, who may create opportunities for comparison but not follow through with the explicit direction for how students should identify structural correspondences between mathematical representations (Ball, 2000; Smith, Hughes, Engle, Stein, 2009; Stein, Engle, Smith \& Hughes, 2008).

\subsection{Strategies for Supporting Mathematical Instructional Analogies}

This paper considers and tests strategies for providing explicit cues that will improve the effectiveness of mathematical instructional analogies. This will also provide some clarity for translating research findings into practice for future teachers. An experiment tests the impact of using a combination of common teacher behaviors identified as being used frequently in the highest achieving countries, but not in the lower-achieving countries, within the video-data collected as part of the Third International Mathematics and Science Study-R (Hiebert et al, 2005). The most common of these practice included making key mathematical representations visible (written on the board or elsewhere), making multiple representations visible simultaneously, aligning these representations so that their similarities are emphasized, and using gestures that move back and forth between these representations. Since there are no outcome data that can be directly linked to the TIMSS-R data, at present there is no direct data available that these will promote learning in children.

These tested practices are described in more detail below. This paper then reports an experiment evaluating the hypothesis that the most pedagogically common of these strategies will improve children's mathematics learning when supporting an analogy in a classroom setting outside of those countries. Specifically, fifth-grade U.S. students were given instruction on a traditionally challenging concept, division of fractions, through a videotaped instructional analogy that did or did not include these support strategies. Learning was tested immediately and after a delay to evaluate impact on both understanding and retention. Finally, implications for optimizing teachers' everyday instructional analogies are considered.

The strategies tested in the current paper derived from studies of actual classroom practices in order to move toward feasible, practice-relevant approaches. The video portion of the Trends in International Mathematics and Science Study (TIMSS 1999; Hiebert et al, 2003) provided an opportunity to systematically study everyday classroom teaching practices in seven countries. Insights from the main dataset are informative about teachers' practices of using problems to draw connections (Hiebert et al, 2005) and a secondary analysis provides specific data on instructional analogies (Richland et al, 2007).

The most recent TIMSS study (Hiebert et al, 2005) compared teaching practices in seven countries with a range of student mathematics achievement profiles, with the United States and Australia regularly scoring behind Japan, Hong Kong, the Netherlands, Czech Republic, and Switzerland. Importantly, the only reliable difference that correlated with national variations in student achievement was how they supported students in making mathematical connections. In two steps, coders measured how likely teachers were to use and support learning from "making connections problems" - problems with the potential to draw connections across math facts, procedures, or concepts. Coders first identified the frequency with which teachers used these problems, and second, they scored the way that the problems were actually instructed by looking at teacher questions and/or discussion to assess the likelihood that students were actually engaged with making the intended connections.

The data revealed that teachers in all countries used these making connections problems, but there were large differences in the way the teaching of the problems was enacted. Teachers in all of the highest-achieving countries were significantly more likely to instruct the problems such that the connections were explicitly drawn 
out than in Australia, and Australian teachers were numerically more likely to do so than teachers in the United States. In fact, U.S. teachers did so approximately zero percent of the time. This was the single pattern in the TIMSS 1999 analyses that mirrored student achievement levels, suggesting that drawing connections may be related to high quality teaching, though direct outcome data were not available in this dataset (Hiebert et al, 2003; Hiebert et al, 2005). Most importantly, this analysis reveals that providing opportunities for drawing connections through using high quality problems is not the same as teaching in ways that enable students to make these connections.

A closer analysis of teacher practices of drawing connections through analogies in a subset of these data also revealed variations in whether teachers supported students in performing analogical thinking when teachers made these opportunities. In a study of the U.S., Hong Kong and Japan, Richland, Zur \& Holyoak (2007) identified all instructional analogies, and then coded these for the presence or absence of six pedagogical practices, instructional strategies, likely to support students' analogical thinking based on the experimental literature. As noted above, simply making an analogy available to learners does not reliably produce the desired connected reasoning (e.g., Gick \& Holyoak, 1980, 1983; Reed, 1989; Ross, 1987, 1989, Zook \& DiVesta, 1991).

The three of these strategies examined in this paper are described briefly. The first two pedagogical strategies reduce processing demands on learners. Dual task and cognitive neuropsychological methodologies have produced evidence that analogical reasoning imposes high processing demands on the working memory and central executive systems for two aspects of analogical reasoning: representing and integrating relevant relations, and controlling attention to competitive, irrelevant information (e.g., Cho, Holyoak \& Cannon, 2007; Halford, 1993; Halford, Wilson \& Phillips, 1998; Krawczyk, Morrison et al, 2008; Richland, Morrison \& Holyoak, 2006). In mathematics education, therefore, the instructor must be cognizant of children's developing working memory capacity that limits their ability to hold and manipulate complex representations in mind (English \& Halford, 1995). Two strategies for doing so were coded: Strategy 1) making compared representations visible on the board or elsewhere, and Strategy 2) keeping multiple representations visible simultaneously, so that learners can reference one while trying to understand the second, without having to hold it in working memory.

The next code measured linking gestures as a tool for helping learners notice and attend to the analogy, reducing general processing demands as well as more specifically directing attention to move between the conceptually related representations. Strategy 3) was: use gestures that move between a source and target representation. Linking gestures are thought to draw learners' attention to the objects being compared (Alibali \& Nathan, 2007).

Results from analyses of these strategies used across Hong Kong, Japanese, and US teachers revealed that while there were no significant differences in the number of analogies per lesson used by teachers in the three regions, the use of coded principles for supporting these analogies varied greatly. Japanese and Chinese teachers were both statistically significantly more likely to use all of the coded practices than were U.S. teachers. Thus as in the larger TIMSS 1999 dataset findings, these results suggest again that supporting student thinking during classroom analogies may be an important element of mathematics achievement. Again, however, these data are not causal, since no direct outcome data were available to link classroom practices to student learning.

The current manuscript describes an experiment testing these strategies in a classroom mathematics setting with U.S. fifth-grade students. The experiment examined the impact of a high quality analogy to teach division of fractions by drawing connections to division of natural numbers. The analogy was either highly or minimally cued. Drawing on the methodology used in prior experiments with undergraduates (Richland \& McDonough, 2010), the instruction was provided by videotape to maintain experimental control and enable random assignment to treatment condition within classrooms.

Division of fractions as a content area was selected for study because this is a concept frequently taught algorithmically, and is difficult to teach so that students understand more than rote use of the algorithm (National Research Council, 2001). The National Council of Teachers of Mathematics (NCTM, 2000) recommended the tested analogy, framing division of rational numbers as similar to division of natural numbers by considering how many times the dividend can be divided into parts the size of the divisor. Division of fractions was also recently identified as a challenge area and as a "major goal for K-12 mathematics education" (National Mathematics Advisory Panel, 2008, p. xvii). Further, based on this difficulty, successful posttest performance could be attributed to the instruction, versus basic quantitative intuitions. 


\section{Methods}

\subsection{Participants}

Participants were recruited from two fifth-grade classes within an independent school in an upper-middle class urban environment. Thirty-four 11-12 year old boys and girls participated. Four participants were excluded for failing to complete the delayed posttest due to absence.

\subsection{Materials}

Video. Two instructional videos were developed, one for a "minimal cuing" condition, and one for a "high cuing" condition. An unfamiliar mathematics teacher taught an instructional analogy derived from an NCTM recommendation to align concepts of division with natural numbers and division of rational numbers. Both videos lasted approximately ten minutes.

In the videos for both conditions the teacher presented the same two division problems: $24 \div 8=?$ and $1 / 3 \div 1 / 6$ $=$ ? The content covered in both videos was the same. Thus, in both conditions the student could have noticed similarities and an analogy between these two problems. Both were certainly categorized as division. In both conditions the student was given an embedded assessment opportunity to solve the division of fractions problem on paper while the video paused before being given the solution, so a measure was taken of immediate learning.

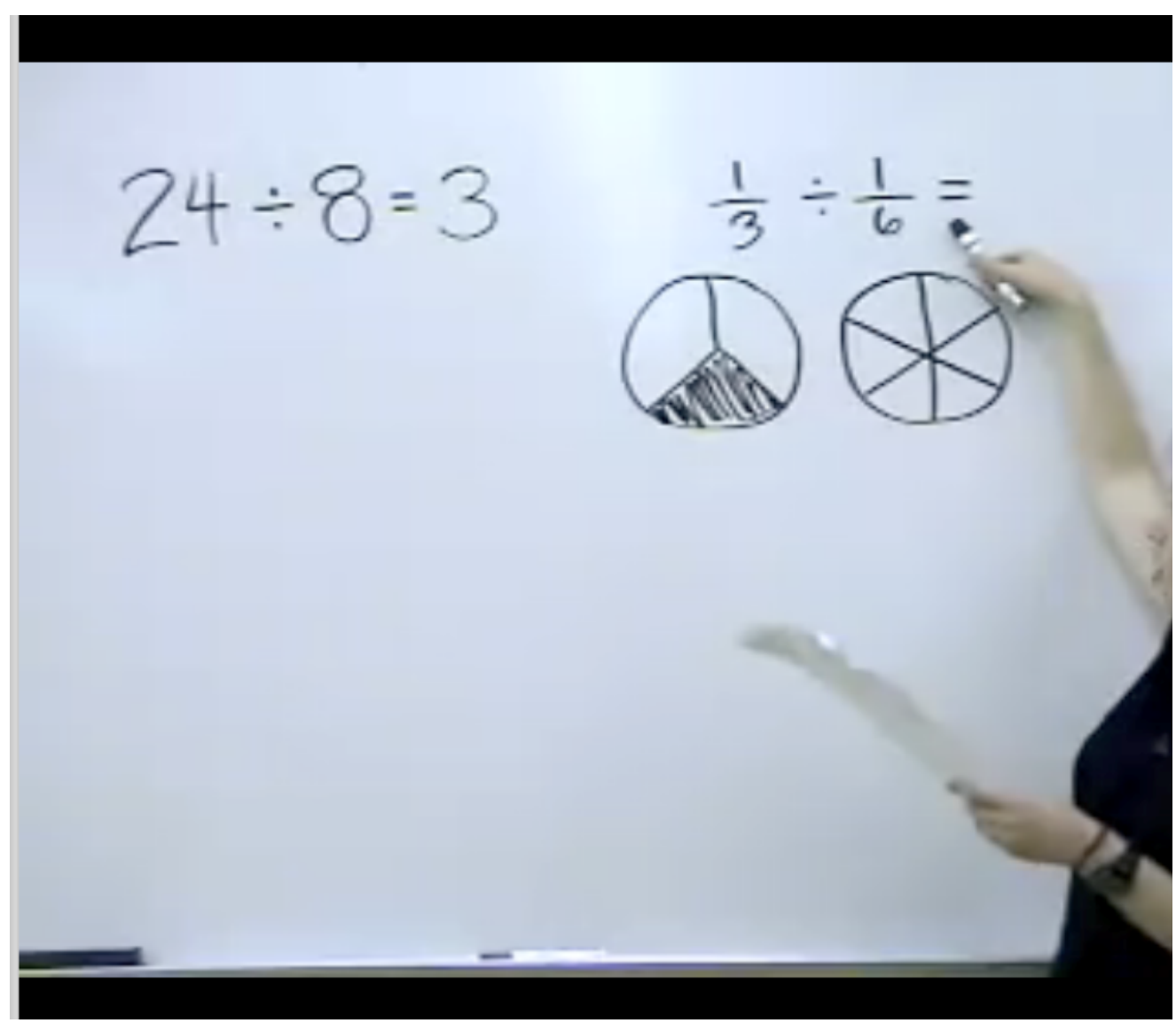

Figure 1. Screen picture of material in high cuing instructional video, comparing two representations of division

The experimental manipulation took place in the details of how the teacher supported the children's analogical reasoning. The "high cuing" condition included a composite of all but one of the recommendations identified in Richland, Zur and Holyoak's (2007) video analyses. The teacher used a highly familiar context (division of natural numbers) as a source. She created a visual representation of the source context by writing the problem on the board while describing it using a specific relational structure ("one way to think about dividing 24 by 8 is to ask how many groups of 8 can fit into a set of 24"). The equation was then left visible on the board while teaching the target problem - division of fractions ("how many groups of $1 / 6$ can fit into a set of $1 / 3$ ?"). Students were expected to require greater support to visualize the groups and set size for the target problem, so the 
equation was accompanied by two circles divided into segments, the first divided into $1 / 3 \mathrm{~s}$, and the second divided into 1/6s. The first had one of the thirds shaded. See Figure 1 for a screenshot of the board during the videotaped instruction. The teacher then showed that two $1 / 6$ size segments could be shaded to cover the same space as the $1 / 3$ (the bottom two 1/6s). The two representations of the equations were written on the board in a similar way so that children could easily identify their common structure. Lastly, the teacher gestured between the two problems (divisor to divisor, dividend to dividend) to further clarify their structural similarity. Thus the cuing support strategies used to develop the composite "high cuing" condition included all but the imagery strategy identified in the video data.

In contrast, in the "minimal cuing" video the teacher first taught the fraction problem $(1 / 3 \div 1 / 6=$ ?) the same way as in the high cuing video. The teacher then gave the division of natural numbers problem $(24 \div 8=?)$ with the statement, "lets finish with an easy one." The teacher did not provide the above cues to support the relational thinking and to help the students leverage their prior knowledge about division of natural numbers to better understand the new context. The fraction problem was not left visible to the student while solving the natural numbers problem.

Assessments. A pretest, a posttest, and a posttest following a delay were constructed. On those tests, two main types of problems were administered on all tests and two additional types of problems were added to the posttests. Problem types that were not repeated across at least two of the tests were not included in the analyses, and two problems were excluded from analyses due to floor performance in both conditions. The pretest contained four total questions that were analyzed, the posttest contained five, and the delayed posttest contained six. Table 1 describes all questions analyzed in this paper.

Table 1. The distribution of analyzed problems that were administered on each test

\begin{tabular}{lllll}
\hline & $\begin{array}{c}\text { Background } \\
\text { Knowledge of } \\
\text { Fractions }\end{array}$ & $\begin{array}{l}\text { High Similarity } \\
\text { problems }\end{array}$ & $\begin{array}{l}\text { Low Similarity } \\
\text { Problem }\end{array}$ & Word Problem \\
\hline $\begin{array}{l}\text { Sample } \\
\text { Problem }\end{array}$ & $\begin{array}{l}\text { Please shade } 1 / 3 \\
\text { of this circle }\end{array}$ & $\begin{array}{l}1 / 2 \div 1 / 8=\text { with } \\
\text { circle } \\
\text { representation }\end{array}$ & $\begin{array}{l}5 \div 1 / 5=\text { with } \\
\text { triangle or circle } \\
\text { representation }\end{array}$ & $\begin{array}{l}\text { How many shelves can be } \\
\text { made from a } 5 m \text { board if } \\
\text { each shelf is } 1 / 4 \mathrm{~m} \text { long }\end{array}$ \\
Pretest & 2 & 1 & 1 & 1 \\
Posttest & 1 & 2 & 1 \\
$\begin{array}{l}\text { Delayed- } \\
\text { Posttest }\end{array}$ & 1 & 2 & & 1 \\
\hline
\end{tabular}

On the pretest, two questions were administered to ensure very basic background knowledge of fraction representations on all tests. These baseline knowledge questions asked students to shade parts of a diagram to represent fractions. Students were asked to shade one fourth of a circle, and 1/3 of a rectangle.

All three tests (pretest, posttest, delayed posttest) included one high similarity problem that had the same mathematical structure and form as the fraction problem taught in the instruction. These problems consisted of the same type of rational numbers taught in the training video - fractions smaller than one - and the same picture, two circles - one to represent the dividend and one to represent the divisor. The dividend was always greater than the divisor. The problem on the pretest was $1 / 2 \div 1 / 8=$ , and participants saw two circle representations, one divided into $1 / 2$ and one divided into $1 / 8$ s. Participants were always asked to use the diagram to show their answer. All high similarity problems took the same form but the numbers were changed for each problem.

All tests also included low similarity problems. The pretest included one problem, and the posttests each had two. The low similarity problems involved a conceptual change in representation from the problem taught during the instruction. The dividend was increased to a value greater than one. In half the problems, the provided representation showed multiple objects (rectangles or triangles), and in the other half, the representation depicted the two circles used in training. For example, the problem calculation on the posttest was $5 \div 1 / 5=$ which necessitates the use of five rectangles to represent the dividend if a whole rectangle represented "one" as it had for the instructed problem. The five rectangles were provided next to the problem for participants' use, but the rectangles were not divided into $1 / 5 \mathrm{~s}$. On the problems that used a representation other than the circles as 
was included in the training, participants received a scaffold. Students were first asked to "shade $1 / 5$ of the following object" (e.g., a rectangle), and then were asked to: "Imagine the above rectangle was one of the rectangles in the next set to help you with the next problem." This was intended to help them make the leap of inference from the process of dividing when the divisor was greater than one. To maximize comparability across tests, all other low similarity problems used the same form (integer divided by fraction $=$ ) but with different numbers and shapes (e.g., triangles rather than the rectangles).

Finally, the posttest and delayed posttest each included a word problem. The word problem was always presented last on a different page, and included the same type of calculations as in the extension problems but they were set in different everyday contexts (e.g., "how many shelves can be made from a 5 meter board if each shelf is $1 / 4$ meter long"). The word problem format was designed to provide high scaffolding to allow participants to solve the problem with or without use of an algorithm. Participants were asked to answer step-by-step questions that asked them to 1) translate the problem into a mathematical equation, 2) draw a representation, and $3)$ provide a solution to the word problem.

Test responses for all questions were coded on a scale from 0-1. A code of 1 was given for an accurate numerical answer, .5 was given for either an accurate numerical answer with an incorrectly drawn representation or only a correctly drawn representation, and 0 was given for both incorrect or a blank response. Intercoder reliability was above $96 \%$ agreement when tested on $20 \%$ of the data.

Written instructions differed on each test. Instructions on the pretest simply asked participants to try their best. The posttest began with the same instructions but also included an explicit hint to 'use the video to help solve these problems'. Since this was both an assessment and an opportunity for participants to practice the division of fractions strategy, it was deemed important that students at minimum noticed the relevance of the video to the posttest. The delayed posttest instructions were the same as the pretest instructions and did not include the hint. Thus the delayed posttest tested the limits of the instruction on participants' retention and ability to notice the relevance of the video to the division of fraction problems.

\section{Procedure}

In a between-subjects design, participants were randomly assigned to one of the two instructional conditions (Minimal Cuing Condition, $\mathrm{N}=16$; High Cuing Condition, $\mathrm{N}=14$ ). Participants were tested in a group classroom setting during mathematics instructional time with each student assigned to his or her own computer with headphones. The computer was only used to allow students to view the experimental or control videos during the instruction phase in order to maintain consistency between participants within each condition. All tests were administered in paper-pencil form with unlimited time. Problems were administered in the same order for all participants. The pretest was administered a day prior to instruction. One posttest was administered immediately after instruction, the second after a one-month delay.

\section{Results}

There was no difference between conditions on the assessment question embedded during the instructional video in which students attempted to solve the fraction division problem independently after some instruction, as both groups scored highly, (High Cuing: $M=88 \%, S D=.29$; Minimal Cuing: $M=100 \%, S D=0$ ). However, in order to ensure equality between the groups, only participants who scored $100 \%$ on this embedded assessment were included in the following analysis (3 participants were excluded). Because the embedded assessment was administered immediately following instruction on the same problem with information still visible on the computer, failure to solve the problem correctly indicated a lack of attention to the original instruction.

\subsection{Impact of the Training Intervention}

A Shapiro-Wilk test of normality, for use with small sample sizes, indicated that the pretest, posttest and delayed posttest data were not normally distributed (Shapiro-Wilk, 1965), (pretest: $\mathrm{W}=.82, p<.001$; posttest: $\mathrm{W}=.78$, $p<.001$; delayed posttest: $\mathrm{W}=.86, p<.01$ ). Thus all further analyses were conducted with non-parametric statistics.

A related-samples Friedman's two-way analysis of variance by ranks, executed stepwise step-down, examined differences between average test performance on the pretest, the posttest, and the posttest after delay. Collapsed across conditions, the tests revealed the analogy led to significant learning from the pretest to both posttests for high similarity problems, $X^{2}(2)=14.5, p=.001$ (pretest: $M=.53, S D=.48$; posttest: $M=.96, S D=.19$; delayed posttest: $M=.67, S D=.46)$. Low similarity problems showed the same pattern of growth, $X^{2}(2)=22.2, p<.001$ (pretest: $M=.22, S D=.42$; posttest: $M=.71, S D=.32$; delayed posttest: $M=.42, S D=.44$ ). 
The word problems were not measured on the pretest so pretest-posttest gains could not be assessed, but a related-samples Wilcoxon Signed Ranks Test (Wilcoxon, 1945) revealed no differences among the posttest and delayed posttest word problem scores $\left(\mathrm{W}_{+}=30, p=.27\right.$; posttest: $M=.61, S D=.45$; delayed posttest: $M=.75$, $S D=.42)$.

\subsection{Relationship between Experimental Condition and Test Performance}

A logistic regression was next used to determine which variables significantly predicted high versus low cuing condition membership. Variables regressed on condition were 1) pretest average performance (average of high and low similarity problem), 2) posttest high similarity problem average (average of high similarity problem scores on posttest and delayed posttest), 3) posttest low similarity problem average (average of low similarity problem scores on posttest and delayed posttest), and 4) posttest word problem average (average of word problem scores on posttest and delayed posttest). See Table 2 for means. Table 3 summarizes the results of these analyses.

Table 2. Means and standard deviations for high and low cuing groups

\begin{tabular}{lll}
\hline & $\begin{array}{l}\text { High Cuing } \\
\mathrm{n}=13\end{array}$ & $\begin{array}{l}\text { Minimal Cuing } \\
\mathrm{n}=14\end{array}$ \\
\hline Baseline: Pretest Average & $.44\left(.38^{*}\right)$ & $.32(.36)$ \\
Posttest High- Similarity Problems & $.77(.26)$ & $.86(.21)$ \\
Posttest Low- Similarity Problems & $.68(.30)$ & $.46(.33)$ \\
Posttest Word Problems & $.62(.33)$ & $.75(.34)$ \\
\hline
\end{tabular}

* Standard deviations reported in parentheses.

The overall fit of the regression model was indicated by a nonsignificant finding on the Hosmer-Lemeshow goodness of fit test, for use in small sample size models regressing continuous predictor variables on a dichotomous test variable (Hosmer-Lemeshow, 2000), $X_{H L}^{2}(7)=6.40, p=.49$. The nonsignificant finding suggests that the model prediction is not significantly different from the observed values of the selected variables, therefore the model fits the data.

The pretest did not predict condition membership, indicating that the initial randomization across conditions was adequate and that there were no preliminary differences between conditions.

Table 3. Binary logistic regression results: Prediction of membership in experimental (high cuing) condition

\begin{tabular}{lllclll}
\hline Predictors & $B$ & S.E. & Wald & df & Sig. & $\operatorname{Exp}(B)$ \\
\hline Average pretest score & -.53 & 1.47 & .13 & 1 & .72 & .59 \\
Average posttest high similarity & 2.65 & 2.40 & 1.22 & 1 & .27 & 14.20 \\
Average posttest low similarity & -3.84 & 1.84 & 4.31 & 1 & .04 & $.02^{*}$ \\
Average word problem & 2.30 & 1.79 & 1.67 & 1 & .44 & 10.02 \\
Constant & -1.30 & 1.70 & .59 & 1 & .44 & .27 \\
\hline
\end{tabular}

$* p>.05$

Among the individual variables, only the low similarity composite variable predicted condition membership, as shown in Figure 2. The odds that students scored highly on low similarity problems following instruction were significantly higher in the high cuing condition than in the low cuing condition such that each low similarity problem scored correctly on the posttests increased the likelihood that participants were in the high cuing condition by .021. No associations existed between students' performance on high similarity problems or word problems on either the immediate or delayed posttest. 


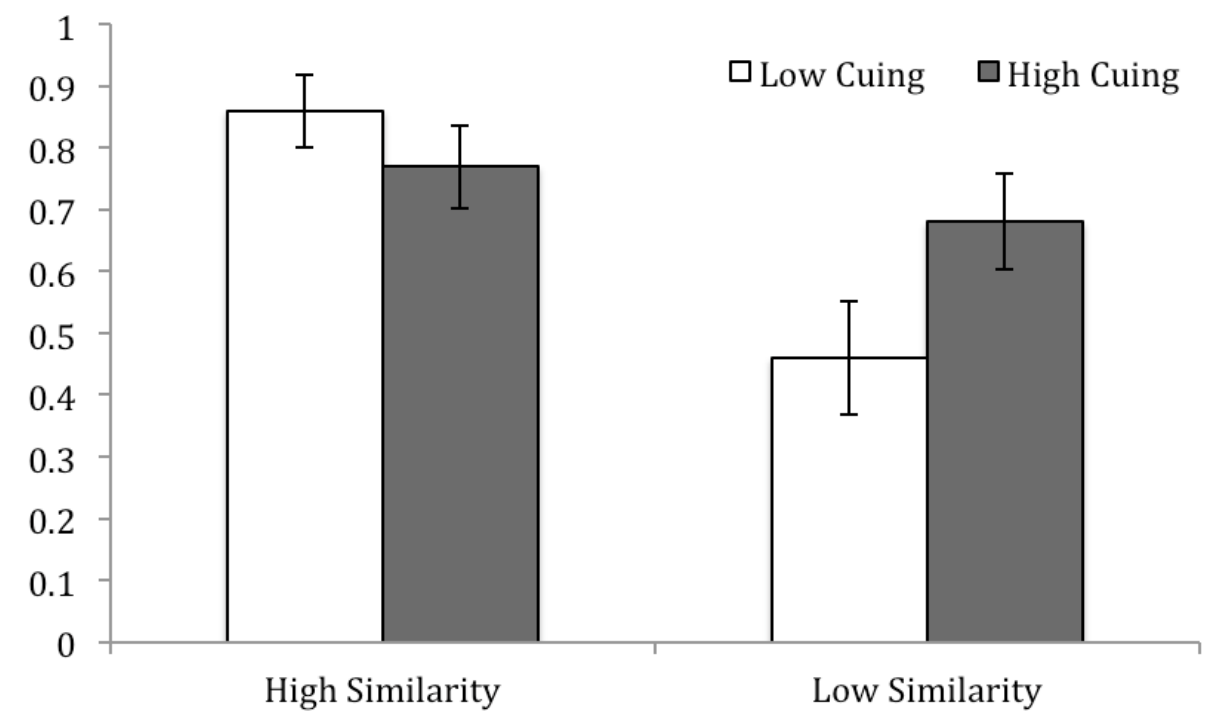

Figure 2. Mean differences on posttest items by condition

\section{Discussion and Conclusions}

The experimental results indicate that the division of fractions analogy was effective for all learners, such that when collapsed across conditions, participants gained from pretest to the posttest on both high and low similarity problems. Further, students in the high cuing condition outperformed those in the low cuing condition on low similarity problems - problems that required an extension from the instruction, though their performance didn't differ on problems that appeared similar to the instruction.

These data replicate and extend the results of Richland and McDonough (2010) to a classroom context with upper elementary school children and a fraction operation context. As discussed in that paper, the patterns of posttest results lend insight into the cognitive benefits of providing support cues. Specifically, the results allow for teasing apart whether pedagogical cues helped learners develop better memory for the instructed strategy or more expert-like ways of focusing on the schematic elements of a new problem. The evidence does not support the interpretation that cuing strategies improved learners' memory for the instructed strategy, since one would expect high cuing to be related to all types of posttest problems, most particularly the high similarity problems that relied mainly on retention of the instructed solution strategy, which was not the case.

Thus rather, these data support the interpretation that high cuing led to more expertlike, schematized representations that facilitated students in generalizing and extending the instruction solution strategy, leading to a relationship between low similarity problems and the high cuing condition. Many have argued that learning from analogies helps learners develop more schematic knowledge representations, meaning that rather than retaining the details of taught problems, students will rather primarily remember the main rule or underlying principle in abstract terms (e.g., Gick \& Holyoak, 1983; Vanderstoep \& Seifert, 1993). This can aid the learner in generalizing to another context, since their understanding of the problem is not tied to the surface context or appearance of the problem (e.g., whether its a problem about trains, see Bassok, 1997), but rather to the abstract mathematical structure.

At the same time, learners did not seem to have developed purely schematic representations of the instructed problem, because they showed different patterns of performance on high versus low similarity problems. This suggests that learners in both conditions stored the mathematical concept along with the main instructional problem and diagram. If they had not, there should have been no difference between the high and low similarity problems.

Participants in the high cuing condition did, however, reveal more flexible knowledge that allowed them to notice similarities based on mathematical commonalities between a new extension problem and the instruction, and to draw inferences about how to solve those problems. Domain experts are well known to more readily attend to structure over surface feature when compared with novices (e.g., Chi \& Ohlsson, 2005; Chi Feltovich \& Glaser, 1981; Schoenfeld \& Hermann, 1988). 
Thus, this work provides data about detailed practices for supporting students in developing mathematical representations that more closely resemble mathematics experts through drawing connections between mathematical representations and concepts, which is an instructional construct posited to rest at the heart of mathematical proficiency (National Research Council, 2001). Future work to examine the role of these cognitive support strategies across more analogies and mathematical contexts would strengthen our understanding of how these principles impact learning more broadly. Additionally, a study of algebra problem solving with middle school students suggests that the efficacy of analogies may depend upon the students' proficiency at the beginning of instruction (Rittle-Johnson, Star \& Durkin, 2009). Subsequent studies will need to address the role of students' entry knowledge on the impact of cuing strategies.

At present, however, the goal is to develop strategies that may aid teachers in optimizing their existing practices of using comparative opportunities in mathematics teaching. In a related effort, Stein, Engle, Smith, and Hughes (2008; Smith, Hughes, Engle, \& Stein, 2009) posit the benefits of providing general pedagogical strategies to aid novice teachers in engaging students into the cognitively rich yet instructionally challenging practice of productive mathematical discussions. One of the Stein et al (2008) recommendations is to draw connections, and the currently proposed strategies may support teachers in effectively accomplishing this goal.

The results have classroom implications. First, these data suggest that introducing division of fractions as similar to dividing one natural number into another is powerful for helping students to understand the concept of division operations with fractions. The analogy was effective at boosting performance during, immediately after, and after a month delay for all participants, even when including problems that required a leap of inference to the case where the dividend is greater than one. While seemingly straightforward, this is not often practiced, with textbooks more often introducing division of fractions by building on addition, subtraction, and multiplication of fractions (e.g., University of Chicago School Mathematics Project, 2007).

Second, though the analogy was beneficial for all participants, adding pedagogical cues to support the analogy led to more flexible, expert-like understanding. As described above, these cuing strategies were derived from everyday classroom practices and were designed to align with experimentally-based research on processing strategies and support, while requiring minimal resource and time allocations.

Finally, the data also revealed why teachers may not currently register the need to change their current practices for drawing connections. There were no differences in performance between conditions on the embedded assessment or on an immediate posttest for problems with high similarity to the instructed problem. Even after a month delay there were no differences in performance on high similarity problems. Thus, if teachers in the minimal cuing condition had used only these measures to determine whether participants had learned from the analogy, they would likely have determined that their students had learned adequately and there was no need to add additional support cues. The use of a variety of different kinds of assessment problems that require extension of the instruction and test learners' ability to make inferences are thus essential for a full diagnosis of students' understanding, and testing after a substantial delay is equally important.

\section{References}

Alexander, P. A., \& Buehl, M. M. (2004). Seeing the possibilities: Constructing and validading measures of mathematical and analogical reasoning for young children. In L. D. English (Ed.), Mathematical and analogical reasoning of young learners (pp. 23-45). Mahwah, NJ: Lawrence Erlbaum Associates.

Alibali, M. W., \& Nathan, M. J. (2007). Teachers' gestures as a means of scaffolding students' understanding: Evidence from an early algebra lesson. In R. Goldman, R. Pea, B. J. Barron, \& S. Derry (Eds.), Video Research in the Learning Sciences (pp. 349-365). Mah Wah, NJ: Erlbaum.

Ball, D. L. (2000). Working on the inside: Using one's own practice as a site for studying mathematics teaching and learning. In A. Kelly, \& R. Lesh (Eds.), Handbook of research design in mathematics and science education (pp. 365-402). Dordrecht, Netherlands: Kluwer.

Bassok, M. (1997). Two types of reliance on correlations between content and structure in reasoning about word problems. In L. English (Ed.), Mathematical reasoning: Analogies, metaphors, and images (Ch. 7, pp. 221-246). Hillsdale, NJ: Erlbaum.

Chi, M. T. H., \& Ohlsson, S. (2005). Complex declarative learning. In K. J. Holyoak, \& R. G. Morrison (Eds.), Cambridge handbook of thinking and reasoning (Ch. 14, pp. 371-399). New York, NY: Cambridge University Press.

Chi, M., Feltovich, P., \& Glaser, R. (1981). Categorization and representation of physics problems by experts and novices. Cognitive Science, 5, 121-152. http://dx.doi.org/10.1207/s15516709cog0502_2 
Chiu, S., \& Tron, M. O. (2004). Classroom discourse and the development of mathematical and analogical reasoning. In L. D. English (Ed.), Mathematical and analogical reasoning of young learners (pp. 75-96). Mahwah, NJ: Lawrence Erlbaum Associates.

Cho, S., Holyoak, K. J., \& Cannon, T. D. (2007). Analogical reasoning in working memory: Resources shared among relational integration, interference resolution, and maintenance. Memory \& Cognition, 35(6), 1445-1455. http://dx.doi.org/10.3758/BF03193614

English, L. (Ed.). (1997). Mathematical reasoning: Analogies, metaphors, and images. Mahwah, NJ: Lawrence Erlbaum Associates, Inc.

English, L. D. (Ed.). (2004). Mathematical and Analogical Reasoning of Young Learners. Mahwah, New Jersey: Lawrence Erlbaum Associates.

English, L. D., \& Halford, G. S. (1995). Mathematics education: Models and processes. Mahwah, New Jersey: Lawrence Erlbaum Associates.

Gallistel, C. R., \& Gelman, R. (2005). Mathematical Cognition. The Cambridge handbook of thinking and reasoning, 23, 559-588.

Gelman, R., \& Gallistel, C. R. (1978/1986). The child's understanding of number. Cambridge, Mass: Harvard University Press.

Gentner, D. (1983). Structure-mapping: A theoretical framework for analogy. Cognitive Science, 7, 155-170. http://dx.doi.org/10.1207/s15516709 $\operatorname{cog} 0702 \_3$

Gentner, D., \& Rattermann, M. J. (1991). Language and the career of similarity. In S. A. Gelman, \& J. P. Byrnes (Eds), Perspectives on thought and language: Interrelations in development (pp. 225-277). London, Cambridge University Press. http://dx.doi.org/10.1017/CBO9780511983689.008

Gick, M. L., \& Holyoak, K. J. (1980). Analogical problem solving. Cognitive Psychology, 12, 306-355. http://dx.doi.org/10.1016/0010-0285(80)90013-4

Gick, M. L., \& Holyoak, K. J. (1983). Schema induction and analogical transfer. Cognitive Psychology, 15, 1-38. http://dx.doi.org/10.1016/0010-0285(83)90002-6

Halford, G. (1993). Children's understanding: The development of mental models. Hillsdale, NJ: Lawrence Erlbaum Associates Inc.

Halford, G. S., Wilson, W. H., \& Phillips, S. (1998). Processing capacity defined by relational complexity: Implications for comparative, developmental, and cognitive psychology. Behavioral and Brain Sciences, 21(6), 803-831. http://dx.doi.org/10.1017/S0140525X98001769

Hiebert, J., Gallimore, R., Garnier, H., Givvin, K. B., Hollingsworth, H., Jacobs, J., Chui, A. M. Y., Wearne, D., Smith, M., Kersting, N., Manaster, A., Tseng, E., Etterbeek, W., Manaster, C., Gonzales, P., \& Stigler, J. W. (2003). Teaching mathematics in seven countries: Results from the TIMSS 1999 video study. (NCES 2003-013). Washington, DC: U.S. Department of Education.

Hiebert, J., Stigler, J., Jacobs, J., Givvin, K. B., Garnier, H., Smith, M., Hollingsworth, H., Manaster, A., \& Gallimore, R. (2005). Mathematics Teaching in the United States Today (and Tomorrow): Results From the TIMSS 1999 Video Study. Educational Evaluation and Policy Analysis, 27(2), 111-132. http://dx.doi.org/10.3102/01623737027002111

Hilbert, D. (1900). Mathematical Problems. Lecture delivered before the International Congress of Mathematicians, Paris, France.

Hosmer, D. W., Jr., \& Lemeshow, S. (2000). Applied Logistic Regression (2nd ed.). New York: John Wiley \& Sons. http://dx.doi.org/10.1002/0471722146

Krawczyk, D. C., Morrison, R. G., Viskontas, I., Holyoak, K. J., Chow, T. W., Mendez, M., Miller, B. L., \& Knowlton, B. J. (2008). Distraction during relational reasoning: The role of prefrontal cortex in nterference control. Neuropsychologia, 46, 2020-2032. http://dx.doi.org/10.1016/j.neuropsychologia.2008.02.001

National Council of Teachers of Mathematics. (2000). Principles and Standards for School Mathematics. Reston, VA., NCTM.

National Mathematics Advisory Panel. (2008). Foundations for Success: The Final Report of the National Mathematics Advisory Panel. U.S. Department of Education: Washington, DC. 
National Research Council. (2001). Adding it up: Helping children learn mathematics. In J. Kilpatrick, J. Swafford, \& B. Findell (Eds.), Mathematics learning study committee, center for education, division of behavioral and social sciences, and education. Washington, DC: National Academies Press.

Novick, L. R., \& Holyoak, K. J. (1991). Mathematical problem solving by analogy. Journal of Experimental Psychology: Learning, Memory, and Cognition, 17, 398-415. http://dx.doi.org/10.1037/0278-7393.17.3.398

Polya, G. (1954). Mathematics and Plausible Reasoning: Induction and Analogy in Mathematics (Vol. 1) Princeton University Press.

Reed, S. K. (1989). Constraints on the abstraction of solutions. Journal of Educational Psychology, 81, 532-540. http://dx.doi.org/10.1037/0022-0663.81.4.532

Richland, L. E., Holyoak, K. J., \& Stigler, J. W. (2004). Analogy generation in eighth-grade mathematics classrooms. Cognition and Instruction, 22(1), 37-60. http://dx.doi.org/10.1207/s1532690Xci2201_2

Richland, L. E., \& McDonough, I. M. (2010). Learning by analogy: Discriminating between potential analogs. Contemporary Educational Psychology, 35, 28-43. http://dx.doi.org/10.1016/j.cedpsych.2009.09.001

Richland, L. E., Morrison, R. G., \& Holyoak, K. J. (2006). Children's development of analogical reasoning: Insights from scene analogy problems. Journal of Experimental Child Psychology, 94, 249-271. http://dx.doi.org/10.1016/j.jecp.2006.02.002

Richland, L. E., Stigler, J. W., \& Holyoak, K. J. (2012). Teaching the Conceptual Structure of Mathematics, Educational Psychologist. http://dx.doi.org/10.1080/00461520.2012.667065

Richland, L. E., Zur, O., \& Holyoak, K. J. (2007). Cognitive Supports for Analogies in the Mathematics Classroom. Science, 316, 1128-1129. http://dx.doi.org/10.1126/science.1142103

Rittle-Johnson, B., Star, J. R., \& Durkin, K. (2009). The importance of familiarity when comparing examples: Impact on conceptual and procedural knowledge of equation solving. Journal of Educational Psychology, 101(4), 836-852. http://dx.doi.org/10.1037/a0016026

Ross, B. H. (1987). This is like that: The use of earlier problems and the separation of similarity effects. Journal of Experimental Psychology: Learning, Memory, and Cognition, 13, 629-639. http://dx.doi.org/10.1037/0278-7393.13.4.629

Ross, B. H. (1989). Distinguishing types of superficial similarities: Different effects on the access and use of earlier problems. Journal of Experimental Psychology: Learning, Memory, \& Cognition, 15, 456-468. http://dx.doi.org/10.1037/0278-7393.15.3.456

Schoenfeld, A. H., \& Hermann, D. J. (1982). Problem perception and knowledge structure in expert and novice mathematical problem solvers. Journal of Experimental Psychology: Learning, Memory, \& Cognition, 5, 484-494. http://dx.doi.org/10.1037/0278-7393.8.5.484

Shapiro, S. S., \& Wilk, M. B. (1965). An analysis of variance test for nomality (complete samples), Biometrika, 52, 591-611.

Skemp, R. (1976). Relational Understanding and Instrumental Understanding. Mathematics Teaching, 77, 20-26.

Smith, M. S., Hughes, E. K., Engle, R. A., \& Stein, M. K. (2009). Orchestrating discussions. Mathematics Teaching in the Middle School, 14(9), 548-556.

Stein, M. K., Engle, R. A., Smith, M. S., \& Hughes, E. K. (2008). Orchestrating productive mathematical discussions: Helping teachers learn to better incorporate student thinking. Mathematical Thinking and Learning, 10(4), 313-340. http://dx.doi.org/10.1080/10986060802229675

University of Chicago School Mathematics Project. (2007). Everyday Mathematics grade 6. Chicago, IL: Wright Group/McGraw-Hill.

VanderStoep, S. W., \& Seifert, C. M. (1993). Knowing 'how' versus knowing 'when': Improving transfer of problem-solving principles. Journal of the Learning Sciences, 3, 93-11. http://dx.doi.org/10.1207/s15327809j1s0301_3

Wilcoxon, F. (1945). Individual comparisons by ranking methods. Biometrics, 1, 80-83. http://dx.doi.org/10.2307/3001968

Zook, K. B., \& Di Vesta, F. J. (1991). Instructional analogies and conceptual misrepresentations. Journal of Educational Psychology, 83, 246-252. http://dx.doi.org/10.1037/0022-0663.83.2.246 


\section{Copyrights}

Copyright for this article is retained by the author(s), with first publication rights granted to the journal.

This is an open-access article distributed under the terms and conditions of the Creative Commons Attribution license (http://creativecommons.org/licenses/by/3.0/). 